\title{
Social worker experiences in disaster management: Case studies from Aotearoa New Zealand
}

Kathryn Hay ${ }^{1}$, Katheryn Margaret Pascoe ${ }^{2}$, Liz McCafferty ${ }^{3}$

\begin{abstract}
INTRODUCTION: Despite minimal public attention, many social workers in Aotearoa New Zealand have been active contributors to disaster management practice. Disaster management comprises four stages: risk reduction; readiness; response; and recovery. Social workers, as professionals in multiple fields of practice, may be engaged in one or more of these stages.
\end{abstract}

METHODS: This article draws from a four-stage project that explored the involvement of registered social workers from Aotearoa New Zealand in disaster management. In the final project stage, 11 social workers were interviewed for the purpose of developing case studies for research and teaching purposes. This article presents the practice observations of two of these social workers in a case study format.

FINDINGS: The experiences of the two social workers emphasises the importance of understanding communities, debriefing and supervision, and having a suite of tools for postdisaster situations. The case studies highlight the complex and vital work undertaken by the social workers following the Canterbury 2011 earthquakes.

CONCLUSION: It is important that social workers understand disaster management and how their skills and knowledge can be transferred into this space. Regular professional supervision, and adequate resources are essential components in the long-term recovery phase of disaster management. Social work as a profession can provide leadership in disaster management through celebrating previous social work practice in this field.

KEYWORDS: Disasters; emergencies; case studies; social work; supervision; disaster planning

Social workers practise across a myriad of fields with individuals and communities. Their roles encompass an array of activities including direct client work, advocacy, community development, policy, research and education. Often social workers are located within multi-disciplinary or interprofessional teams in environments that extend beyond those of the social work profession. Consequently, they may be active contributors to enhancing the wellbeing of people and communities but not necessarily as prominent or visible actors. In other organisational contexts they may be situated as key professionals working alongside other social workers. Although the title of "social worker" became a protected term in Aotearoa New Zealand from 2021 through the Social Workers Registration Legislation Act (2019), many registered social workers have been employed under different titles,

\author{
${ }^{1}$ School of Social Work, \\ Massey University, \\ New Zealand \\ ${ }^{2}$ School of Applied Social \\ and Policy Science, Ulster \\ University, Northern \\ Ireland, UK \\ ${ }^{3}$ School of Social \\ Sciences, University of \\ Otago, New Zealand
}

AOTEAROA NEW ZEALAND SOCIAL WORK 33(1), 17-28.

CORRESPONDENCE TO: Kathryn Hay k.s.hay@massey.ac.nz 
such as whānau worker, support worker, navigator and needs assessor. Whatever their title, social workers as professionals are committed to social justice, human rights and promoting social change (IASSW \& IFSW, 2014). Social workers are trained to support people in times of crisis, to seek solutions to challenges, to advocate for individuals and communities and to undertake this work in accordance with professional codes of ethics and conduct (Dominelli, 2014). Their positioning across fields of practice and in the heart of communities allows them to be critical agents in respect of their core work, but also to have a standing in the field of disaster management (Alston et al., 2019).

A disaster can be defined as "an event that causes major losses to people and destruction of place. It can result from a natural or human-induced event or from intentional human actions" (Alston et al., 2019, p. 5). The effects of disasters may be felt locally, nationally and globally. Multiple government, nongovernment and private organisations may be involved in the mitigation and management of disasters (Hay, 2019). Disaster management is commonly divided into four phases, each of which guides and informs the others (Paul, 2011). Risk reduction and readiness both occur in the pre-disaster phase with a focus on reducing the likelihood of disasters and planning for an event that may lead to a disaster (van Heugten, 2014). Activities in these phases often include policy and organisational development, practice drills, organising emergency kits, information distribution and setting up relevant systems such as tsunami warning sirens or cell phone alerts. The response phase occurs immediately after an event and incorporates all efforts associated with relief and rescue (van Heugten, 2014). The recovery phase focuses on reconstruction, short- and longerterm recovery and any post-disaster developments (van Heugten, 2014).
For decades, social workers have played a pivotal role in disaster management although the role of social work has largely gone unrecognised in the literature until more recently (Alston et al., 2019; Dominelli, 2014). At times this work has been specified as part of their professional role, although often social workers have unexpectedly found themselves working in recovery and response efforts following disaster events (Hugman, 2010). Examples of social worker engagement in disaster events include the creation and implementation of helplines and other immediate support services (Dominelli, 2014; Maher \& Maidment, 2013); the establishment of new planning frameworks and protocols for current and future events (Cooper-Cabell, 2013; Maher \& Maidment, 2013); direct client work with existing and new service users with a particular focus on psychosocial practice addressing trauma, grief and loss (Briggs \& Heisenfelt Roark, 2013; Du Plooy et al., 2014); and community connectedness and development pre- and post-disaster (Alston et al., 2018; Milner, 2013; Shevellar \& Westoby, 2014; Tudor et al., 2015).

In Aotearoa New Zealand, social worker involvement in disaster management has received minimal attention publicly (Hay \& Pascoe, 2018). Further, there is limited awareness from disaster management professionals of what social workers do and how they can be active and deliberate contributors in the disaster management phases (Hay \& Pascoe, forthcoming). This article showcases the experiences of two social workers in disaster management work in Aotearoa New Zealand. The case studies in this article highlight the important practice undertaken by the social workers following disaster events and their subsequent learnings. Themes from the case studies are discussed and offer ideas for consideration by social workers as well as other professionals working within the disaster management domain. The findings from this study are also relevant in the new local and global context created by the Covid-19 pandemic. 


\section{Method}

The development of the case studies was the final stage of a four-part project that focused on different stakeholder perspectives on social workers' engagement in disaster management. The project aimed to map social workers' involvement in disasters in Aotearoa New Zealand and to examine their role, capacity, utility and training needs in the four phases of disaster management. The primary research question was:

How have registered social workers been involved in disaster management in their professional role in NZ?

The first stage of the project comprised a content analysis of the portrayal of social work, social workers and emergencies (disasters) in Aotearoa New Zealand online media between 2006 and 2016. A key finding from this stage was that "social workers and their emergency-related practice remains largely invisible in New Zealand's online media" (Hay \& Pascoe, 2018, p. 5). The media portrayed social workers as being primarily associated with long-term recovery efforts rather than involved in the risk reduction, readiness, reduction and response stages of disaster management.

The second stage of the project generated data from interviews with disaster management professionals who were not social workers. The purpose of these interviews was to elicit their perspectives on what social workers do in their professional role, how they are (or could be) involved in disaster management, the skills and capabilities they offer, and their current profile in disaster management. An important finding from this stage of the project was that social workers needed to "have a stronger profile so that the crosssection of disaster management personnel could better understand what their skills were and how their expertise could be most effectively utilised" (Hay \& Pascoe, forthcoming).
The third stage of the project involved a survey of registered social workers in Aotearoa New Zealand which was distributed through the Social Workers Registration Board in 2018. This survey posed questions about social workers' engagement in disaster management and associated key activities, whether they felt equipped for this work, perceptions of visibility, and the utility of social workers in future disaster events. The results from the 57 participants indicated their involvement in disaster management spanned "direct client work, planning and policy development, training, research, networking, and debriefing" (Hay \& Pascoe, forthcoming). Further, the results suggested that social workers may be underutilised in the disaster management field, but they have multiple skills and attributes that could be of value. Participants in the survey were invited to contact the researcher if they wished to be involved in the fourth and final stage of the project wherein they would engage in a semi-structured interview that was designed to become a case study about their involvement in one or more of the disaster management phases.

A total of 11 registered social workers offered to participate in the final project stage. All had been engaged in the recovery and response phases of disaster management and several had also been active in risk reduction and readiness planning. Several participants had been living and working in Canterbury at the time of the 2010 and 2011 earthquakes and thus experienced these disaster events. Subsequently, they became involved in the recovery and response efforts in their professional roles. Some of the participants who were engaged in the Canterbury community following the major earthquakes were sent to the region by their organisations, usually for a short two- to five-week period. Other case studies focus on the North Canterbury or Kaikoura/Wairau earthquake of 2016 and a flooding situation in the North Island of Aotearoa New Zealand. Following the interviews, the approved transcripts 
were shaped into case studies. A common structure was applied to each case study for consistency and included: the context of the case; the practice environment; practice approaches; challenges; lessons learned; and reflections for other professionals. These areas loosely aligned with the interview schedule. A research assistant drafted the case studies, and these were edited by the first author before being returned to individual participants for further editing. This approach strengthened the trustworthiness and credibility of the analysed data especially as it recognised a level of reflexivity from the authors as they were not present during or after the disasters being discussed by the participants (Braun \& Clark, 2019; Lietz \& Zayas, 2010).

A thematic analysis guided by the framework approach of Ritchie and colleagues (2014) was then applied to all the case studies. This involved familiarisation with the case studies and identification of common concepts and themes (Ritchie et al., 2014). Examples of the emerging themes included social work models, theories and approaches; resilience of social workers; management of staff; understanding of trauma; networking; and organisational systems. Based on this analysis, decisions about which case studies would sit alongside each other in subsequent publications were determined. What follows are two case studies that contain observations from experience upon which is built a discussion about key aspects of the two social workers' experiences. Following initial writing of the publication, feedback from the case study participants was invited to ensure that their perspectives had been accurately represented.

Ethics approval for this project was granted by the Human Ethics Committee at Massey University, New Zealand. Informed consent and confidentiality were important ethical considerations for the design and implementation of the interviews and survey. The participants in the case study stage of the project agreed to be named in any resulting presentations or publications. In addition, they were informed they could have an active role in checking and editing the case studies and share the authorship of any publications.

\section{Social worker case studies - Canterbury earthquakes 2010 and 2011}

\section{Context}

At 4.35 am on 4 September 2010, a magnitude 7.1 earthquake ruptured in Canterbury, a South Island region of Aotearoa New Zealand. The epicentre was located $40 \mathrm{~km}$ west of Christchurch, the largest city in the South Island. Felt throughout the country, significant damage to infrastructure, homes and businesses occurred in and around Christchurch, however, no lives were lost as a direct result of the earthquake. Following months of tremors and aftershocks, further devastation followed on 22 February 2011, when a 6.3 magnitude quake struck approximately $10 \mathrm{~km}$ southeast of Christchurch. Occurring at $12.51 \mathrm{pm}$, many people were at work, school or away from their homes. The collapse of infrastructure and buildings took the lives of 185 people and injured many more. With damage to roads, transport and telecommunication systems, people were unable to directly contact family and friends for hours or even days to check on their welfare or whereabouts. As one of the deadliest natural disasters to have occurred in Aotearoa New Zealand, consequences and recovery efforts continue years after the event.

\section{Social worker 1}

\section{The practice environment}

Social worker 1 is currently a registered social worker employed as a clinical social worker and supervisor in private practice at Aspiring Hauora Health and Wellbeing in the Upper Clutha and Whakatipu, Aotearoa New Zealand. When the September 2010 and February 2011 earthquakes occurred, she was employed as a mental health social worker with the Southern District Heath Board. 
A couple of weeks following the February earthquake, local staff began experiencing exhaustion and there was demand for additional staff to be brought into the Canterbury region to respond to the needs of residents. The social worker was contacted directly by managers of social services in Canterbury and asked to relocate and work in the region. At the time, the district heath boards were sharing staff across districts to manage demand, and so she was able to move to Christchurch to support the response and recovery efforts. By April 2011, the social worker held a permanent role within the child adolescent recovery team in Christchurch. Her work was predominantly focused on young people and their families for short-term intervention.

Working in unstructured, constantly changing contexts and responding to significant demand on services was emotionally and physically draining for the health staff. Simultaneously, they were managing their personal circumstances, with most having lived through both the September 2010 and February 2011 earthquakes. Aftershocks were frequent but unpredictable, with staff and patients experiencing on-going trauma and anxiety. Within the mental health services, young people were presenting with post-traumatic stress disorder (PTSD), anxiety and sleep disruption, with instances of trauma transference from parent to child also evident. Family resilience varied, and work with young people often required addressing family dynamics.

Following the February 2011 earthquake, representatives from a Queensland university and a university in Melbourne were flown from Australia to Christchurch to deliver training for mental health practitioners. This was funded by the Australian and Aotearoa New Zealand governments. A recovery package had been developed by Australian universities following the 2009 bush fires and Cyclone Yasi in Australia. The recovery package addressed the psychological safety of young people and their families, outlining trauma created by natural disasters, what risk factors to look for in individuals and families, how to manage intervention, and forecasting long-term responses. The social worker and her colleagues adopted this package of triage assessments and screening for PTSD and disturbances in young people. Brief intervention was applied, ranging from one to five sessions, often including the young person's parents. For instances where the earthquake had triggered previous traumatic experiences or more complex needs were present, the social worker was able to fast-track the client into the standard mental health services. The Australian team continued to support both the psychological recovery of staff at the District Health Board and the Urban Search and Rescue team.

\section{Practice approaches}

When working in disaster response and recovery, a strong understanding of trauma and the resulting psychological impacts is necessary to inform safe and appropriate practice. This includes understanding coping mechanisms such as denial, as well as triggers to prior negative experiences. Where knowledge is limited, social workers need to engage with literature, research and training to strengthen their practice.

Aside from her social work training, the social worker was trained in psychological first aid which included assessment skills. This approach enabled information gathering to prioritise needs and determine what level of intervention may be necessary. Other skills commonly utilised included minimal encouragers, open questioning, paraphrasing and exploring strengths. Despite having standard procedures and approaches that may be required in everyday practice, during disaster response and recovery, social workers may need to adapt assessment methods, as the presenting situations will vary significantly.

Following a disaster, response and recovery efforts require considerable flexibility to 
respond to chaos. Social workers may be engaged across broader contexts including homes, schools, hospitals and resource centres, with limited office provisions. With the changing environment, resourcing can be disrupted, and unforeseen needs arise, therefore it is important to be mobile and adaptable to work in unstructured settings. Furthermore, roles are often fluid. Social workers may be conducting assessments in the morning, then unloading supplies from a helicopter in the afternoon, as experienced by this social worker and her colleagues.

\section{Challenges}

The September and February earthquakes were followed by approximately 8000 aftershocks. This made the disaster additionally challenging as, unlike a flood, cyclone or bush fire, aftershocks cannot be predicted. Due to the unpredictable nature of aftershocks, it was difficult for social workers and others to prepare for them and many people were continually re-exposed to trauma, increasing the complexity of needs. What may have initially presented as appropriate intervention and support changed rapidly for the social work staff.

The capacity of staff was, at times, limited as many had lived through the disaster and were managing their own personal circumstances including trauma, stress, family and financial struggles. Bringing in social workers from outside Canterbury was necessary to combat local limitations. Additionally, having the support and collaboration of friends, colleagues and neighbours was important for staff to work effectively, as continuing aftershocks saw facilities close and resources reduced. Accessing alternative means of support through these networks was vital, including being able to find childcare to be able to continue working.

\section{Lessons learned}

The social worker identified that strengths may arise from a disaster as she saw firsthand how communities and families can pull together in times of struggle. Described as a "silver lining", community cooperation continued for several months after the initial earthquakes, with neighbours building stronger relationships and supporting one another to access resources or care. During disaster response and recovery, boundaries can often become less rigid. As a social worker it is important to recognise your own humanity as everyone will continue to have their own responses to the situation and the ongoing aftershocks. Showing fear and emotion in front of colleagues and clients may occur more than would be usual in practice. This can create connection and build relationships as emotions and experiences are held in common.

\section{Reflections for other professionals}

A key recommendation for professionals involved in disaster response is to withhold judgement. Reactions to the earthquakes and aftershocks varied between residents. Although involvement in, and following, a natural disaster is a shared experience, not everyone will respond or manage in the same way. Accepting people's reactions as their own is important, as judgement is not helpful to the individual, their family or the intervention. For example, as the social worker explained, a child she worked with presented as constantly anxious about rocks falling on them during aftershocks, even when there were no rocks present. It was not until the child disclosed that he had seen rocks falling down and causing damage near his house during the February earthquake that his anxiety could be understood and contextualised. She summarised: "You don't know anything about a person's life until they tell you." There are no rules outlining what is or is not appropriate to feel during and after a disaster.

Additionally, addressing psychosocial needs and having social workers at the front of response and recovery to triage what people need and knowing where to go for support is important. Local civil defence groups 
could better work with health and welfare based social workers to assist in managing evacuation or resource centres for future disasters.

Lastly, reflecting on the recovery stage of the Christchurch earthquake, the social worker advocated for the continuation of support services to address long-term effects on child and adolescent development and mental health. The full extent of needs was not anticipated or understood following the quakes, with many problems and challenges arising several years after the earthquakes occurred and after many recovery support services had been discontinued. Long-term needs must be considered when developing and resourcing recovery efforts.

\section{Social Worker 2}

Social worker 2 is a registered social worker based in the Canterbury region of Aotearoa New Zealand. Between 2011 and 2017, she was employed in a range of roles focused on elder care including contracts with Age Concern, the older person's health specialist team at Princess Margaret Hospital, and the Mabel Howard day clinic. At the time of the 2011 Canterbury earthquake, the social worker was employed by the Princess Margaret Hospital and was working in the interdisciplinary older person's health specialist team.

\section{Practice environment}

Immediately following the 2011 earthquake, people from damaged aged residential care services and other community-based care and support services were rapidly transferred around Aotearoa New Zealand to alternative facilities including hospitals and residential care facilities. Hospitals in Christchurch were faced with high rates of inpatients with injuries following the earthquake.

The entire Kate Shepherd residential village was evacuated, having been almost submerged because of land movement and liquefaction (where the soil loses its strength and stability, turning into a liquid). Residents were shifted two or three times within a matter of days following the disaster. Poor communication and limited feedback systems resulted in missing information in the recorded relocation data and saw people unaccounted for. Family members also intervened during this time to remove their loved ones from residential care services to provide care themselves. Unfortunately, many people who had taken in their elderly family members were not prepared or equipped to take on the role of carer while also managing their own stressors following the earthquake. Further, community-based elderly people reliant on in-home support services, including medication assistance, meal preparation and personal cares, had their services interrupted with many workers unavailable to attend or unable to travel to the homes of their clients. Many of those people who were relocated or injured were the social worker's existing clients.

Immediately following the earthquake, considerable time was spent phone-calling facilities and homes to locate existing clients and assisting residential services with relocation data and transportation lists. This was vital to map where vulnerable elderly people and elder care residents were, to develop accurate records to communicate with family members, and ensure continuity of care. However, with the influx of elderly patients to the Princess Margaret Hospital, focusing on this task alone was not feasible and social workers also became involved in triaging elderly hospital inpatients. To manage the constant flow of patients in and out of the hospital, stickers were used to identify people and their belongings to reduce the risks of wrong medication or lost possessions in the mass movement of people. Assessing the level of need required flexibility and creativity, by-passing standard procedures during the emergency response to ensure people got adequate care. Social workers often liaised with geriatricians over the phone to complete needs assessments and find beds so that service users could 
access hospital-level care and have their immediate medical needs attended to.

Following the first couple of days locating elderly people and triaging elderly inpatients, the social worker joined an outreach team with army personnel and nurses to check on aged residential care facilities and existing community-based clients still in the Christchurch region. Often faced with highly stressed staff and residents, de-escalating situations to negotiate options for relocation out of destroyed or damaged homes was central to her work. Considerable practical support was also provided by the outreach teams, including sourcing generators, linking residents to other community services and providing assistance by feeding residents in care facilities to enable staff to take lunch breaks.

\section{Practice approaches}

Working with highly stressed people and their families in disempowered or compromised positions often requires efforts to de-escalate the situation before establishing a clear understanding of need or exploring solutions. Reflecting and rephrasing how someone is feeling, what they have said or what they are experiencing, as well as showing empathy and checking one's understanding of information are important skills social workers adopt when working with people in highly stressed, traumatic circumstances.

Social workers are competent in assessment processes and have well-developed questioning skills that can establish risks, needs and required resources. Combined with the creativity and flexibility needed to respond to constantly changing situations, social workers bring a range of assessment skills which enable accurate and quick assessments to prioritise and triage needs in an emergency. Many people were distressed and seeking help without necessarily having had the time to consider what resources, opportunities and skills they already possessed. Assisting people to explore and draw upon their own strengths and support systems or creating new connections with people was central to managing needs in a time of resource scarcity.

Following the earthquakes, knowing what was happening in the neighbourhood, wider community and Christchurch city was essential. Understanding what communities can offer and what local resources are available during response and recovery is an important aspect of social work practice. With the volume of elderly people needing support, the outreach teams were not able to provide regular, repeated visits or meet all the practical needs required. However, by being able to link people to local support groups, resource centres and other agencies or organisations operating in the area, social workers were able to help address need at a local level and reduce isolation by delegating tasks and encouraging community building.

The social worker continued to work in the aged care sector during the long-term recovery phase following the earthquakes. Her position at Age Concern was funded by the Canterbury Earthquake Appeals Trust. It was in this position that she saw perhaps the most devastating impacts of the earthquakes on older people and this was where her social worker skills were essential. The recovery phase can continue for a long period following a disaster, and the skills and expertise that social workers can offer are valuable, both in respect of client work but also skills sharing and education. Having an understanding of the grief process, PTSD, and mental health as well as tapping into community resources and practical assistance are vital to the recovery phase. Social workers are perhaps better equipped than most other professionals to work directly with these issues.

\section{Challenges}

In times of emergency, systems are not necessarily operating as usual, therefore, access to information can be compromised. 
Next of kin details, for example, were not always up to date at hospitals or residential care facilities. Furthermore, social workers may not be able to confirm who is calling to enquire about the location and health of a person in their care. Maintaining privacy and confidentiality can, therefore, become complex. To support the health of older people, particularly in a time of crisis, knowing what community resources, networks and supports are available from existing organisations is important. Some social workers were brought in from other regions to help respond to the earthquakes; however, the roles they could fill were limited as many were not familiar with the local communities and resources. On a personal level, the initial response phase was extremely difficult and there were days, and even hours when the social worker dreaded being at work as she felt incapable of meeting the needs of all the people she was endeavouring to support. Dealing with the high levels of stress with virtually everyone she encountered was very draining.

\section{Lessons learned}

Social workers also need to be offered support during disaster response and recovery efforts: "Working on the frontline, you just keep going. You push through the stress, exhaustion and anxiety to support others, but you do not necessarily give much thought to your own needs." Having lived through the disaster while also working in the community, social workers have their own situation and challenges to manage. Many responders will be living with traumatic memories of what they encountered and the ongoing impacts. Therefore, opportunities for personal one-toone debriefs and on-going supervision and counsel are essential for social workers as well as other responders.

The social worker drew strength from the people she worked alongside following the earthquakes. She appreciated the wisdom and resilience that others shared with her, both colleagues and clients.
While there were many people who found it challenging to cope, others were able to successfully manage their own lives and, at times, transferred learnings from previous experiences to the situation. As an example, an elderly client explained her immediate response to the 2010 earthquake which occurred while she was asleep in bed was exactly the same as what she had been taught to do during bombing raids in London during World War II. Instinctively, she responded by pushing her feet against the wall, thus making space between her bed and the wall which she was able to fall between and remain physically safe. The courage and determination of others can encourage and motivate others, including social workers.

Response efforts following the earthquakes also revealed existing social problems. For instance, as a result of homes being checked for safety, many issues within a person's home were identified that would have ordinarily been undetected. In the social worker's context this related to the elderly, where there was an increased awareness of neglect, isolation and hoarding. This has been an ongoing issue with social workers continuing to encounter these concerns a few years after the quakes.

\section{Reflections for other professionals}

Regular supervision and debriefing should be embedded into disaster planning across all first responders and short- and longterm recovery professionals. A combination of both group debriefing and individual debriefs provides opportunities for workers to express themselves, reflect on what has happened and begin to process the range of effects on them, both personally and professionally. Sharing these debriefing or supervision processes can support the development of workplace support networks.

Needs continue to exist in Christchurch and the wider Canterbury region years after the earthquakes. Funding was initially 
provided to increase services following the disaster, for example the establishment of the Earthquake Support Coordinators who provided practical support with issues such as managing insurance claims, but much of the funding has now ceased, reducing the services and supports available. Despite discontinued or reduced funding, significant needs remain and staff continue to operate under considerable pressure in the face of increased community need.

\section{Discussion and implications}

The case studies signal that social workers can bring immense personal and professional resources into the disaster management field. Trained in crisis management, individual, family or whānau and group work, as well as policy and community development approaches, social workers can span and usefully contribute to all aspects of disaster management, but perhaps most obviously, the response and recovery phases (Dominelli, 2014). The social workers in this article integrated and transferred many of the models and theories they utilise in their usual practice into postdisaster work. Strengths and solutionsfocused perspectives, as well as assessment, communication and networking skills have particular value as shown in the experiences of the two social workers (Tan \& Yuen, 2013). A non-judgemental approach, which focuses on drawing upon people's own resources and supports, sits at the heart of social work practice, and was emphasised in the case studies. This resonates with disaster management approaches that encourage people to take control of their own situations, as much as possible, in preparing for, during and following a disaster event (Blake et al., 2017). As the case studies highlighted however, people's needs may not be known until a disaster event occurs. To remain non-judgemental and then be able to respond appropriately, it is important that social workers understand the structural and socio-political conditions that may inhibit individuals or communities from becoming fully prepared prior to an emergency or having the resources or skills to address their own needs independently following an event, such as unresolved trauma, neglect or isolation. Social work education has a vital role in ensuring that new graduates are equipped with beginning competency in the skills, knowledge and values required for engagement in disaster management including understanding how learnings can be transferred across contexts. Post-qualifying opportunities for social work training in disaster management could also assist with continuing professional development in this field.

As illustrated in the case studies, social workers generally hold extensive knowledge of community resources and services and have far-reaching networks and relationships. These connections can be critical after a disaster when resources may be stretched or constrained but when more people require additional support. Being a connector and mobiliser of resources is a key role of a social worker and they are also able to recognise and encourage the existing strengths and resources within communities and prioritise community-building. These skills are invaluable in the different disaster management phases, especially in the medium- and longer-term recovery phase (Dominelli, 2014). While the social workers in the case studies remained within their own organisations during the post-disaster phase, having social workers embedded in local civil defence groups and the National Emergency Management Agency as well as other responding organisations such as the Police and Defence Force would be of considerable benefit. Social workers could then utilise their skills and knowledge in these organisations in all phases of disaster management. Recently, with the Covid-19 pandemic across the world, social workers have been shown to be strategically placed inside a variety of health and social services settings, transferring their knowledge to respond to this particular disaster (Berg-Weger \& Morley, 2020).

As the case studies illustrated, supervision is especially important in times of crisis to 
ensure the safety of workers and the wider community. Following disaster events, usual organisational practices, including supervision, may be challenged due to the inevitable immediacy of other activities and tasks. Adamson (2018) has highlighted that supervision in disaster management is under-addressed in the literature. Given this limitation in the current research, there is opportunity to engage in further exploration of the use of professional supervision in disaster management and especially in organisations that may be less familiar with this construct. The importance of supervision and debriefing cannot be underestimated especially in the post-disaster context when additional pressures are added to workers' personal and professional lives.

Finally, ongoing resourcing, especially in the longer-term recovery phase, was noted as a considerable challenge by the two social workers. Social workers frequently work in environments constrained by funding and other resources and the impacts of significant disaster events, such as the Canterbury earthquakes further compound the challenges they face. Continuing to have strong connections with organisations such as local civil defence groups and other organisations engaged in disaster recovery efforts especially beyond the initial response and recovery phases, may assist in maintaining an awareness of ongoing impacts on individuals and communities. In addition, social workers may also be able to add another voice to lobbying efforts with local and central governments. Sustaining these relationships will also aid in increasing the understanding of disaster management professionals about what social workers do in their professional role and their critical space in the disaster management field.

\section{Conclusion}

Dominelli (2014, p. 349) argued that "with leadership, commitment and energy, social work can innovate and foster practice in new directions and promote the production of shared knowledge and learning". In the disaster management field and including the current Covid-19 pandemic environment, there is ample opportunity for the social work profession, locally, nationally and globally, to embrace this challenge. In Aotearoa New Zealand, claiming space alongside other disaster management professionals, such as those from local civil defence groups, social workers can amplify relevant models, theories and practice that would strengthen current disaster management approaches. Further, raising awareness of how social workers can contribute to this work will increase future engagement which, in turn, will enable the co-production of solutions and collaborative initiatives. Celebrating the excellent practice of social workers who have been engaged in the disaster management phases serves to raise public awareness of the profession of social work as well as acknowledge the important work already undertaken.

\section{Acknowledgement:}

The authors wish to thank Heather Clay (Aspiring Hauora Health and Wellbeing, New Zealand) and Trina Cox (Former Clinical Assessor at the Canterbury District Health Board - Older Persons Health Specialist Service, New Zealand) for gifting their case studies to this research project.

\section{Declaration of interest:}

The authors report no declarations of interest.

\section{Funding acknowledgement:}

This project was supported by a grant from the Massey University Research Fund.

Accepted 30 March 2021

Published 25 April 2021

\section{References}

Adamson, C. (2018). Trauma-informed supervision in the disaster context. The Clinical Supervisor, 37(1), 221-240. doi:10.1080/07325223.2018.1426511

Alston, M., Hargreaves, D., \& Hazeleger, T. (2018). Post disaster social work: Reflections on the nature of place 
and loss. Australian Social Work, 71(4), 405-416. doi:10.1080/0312407X.2017.1409776

Alston, M., Hazeleger, T., \& Hargreaves, D. (2019). Social work and disasters: A handbook for practice. Routledge.

Berg-Weger, M., \& Morley, J. E. (2020). Loneliness and social isolation in older adults during the COVID-19 Pandemic: Implications for gerontological social work. Journal of Nutrition Health and Aging, 24(5), 456-458.

Blake, D., Marlowe, J., \& Johnston, D. (2017). Get prepared: Discourse for the privileged? International Journal of Disaster Risk Reduction, 25, 283-288. doi:10.1016/j. ijdrr.2017.09.012

Braun, V., \& Clark, V. (2019). Reflecting on reflexive thematic analysis. Qualitative Research in Sport, Exercise and Health, 11(4), 589-597. doi:10.1080/215967 6X.2019.1628806

Briggs, L., \& Heisenfelt Roark, M. (2013). Personal reflections: What happens when disaster hits? New Zealand New Zealand Social Work, 25(2), 98-104.

Cooper-Cabell, N. (2013). Mind the gap: Post earthquake community wellbeing? New Zealand New Zealand Social Work, 25(2), 27-34.

Dominelli, L. (2014). Learning from our Past: Climate Change and Disaster Interventions in Practice. In C. Noble, C. Strauss, \& B. Littlechild (Eds.), Global social work: Crossing borders, blurring boundaries (pp. 341-351). Sydney University Press.

Du Plooy, L., Harms, L., Muir, K., Martin, B., \& Ingliss, S. (2014). "Black Saturday" and its aftermath: Reflecting on postdisaster social work interventions in an Australian trauma hospital. Australian Social Work, 67(2), 274-284. doi:10.1080/0312407X.2013.862558

Hay, K. (2019). Social work and disasters. In R. Munford, \& K. O'Donoghue, (Eds.), New theories for social work practice: Ethical practice for working with individuals, families and communities (pp. 173-194). Jessica Kingsley Publishers.

Hay, K., \& Pascoe, K-M. (2018). Where is social work in emergency management? Exploring visibility in New Zealand online media. Australasian Journal of Disaster and Trauma Studies, 22(1), 3-10. http://trauma.massey. ac.nz/issues/2018-1/AJDTS_22_1_Hay.pdf

Hay, K., \& Pascoe, K-M. (forthcoming). Social workers and disaster management: An Aotearoa New Zealand perspective.

Hugman, R. (2010). Understanding international social work A critical analysis. Palgrave Macmillan.

Lietz, C. A., \& Zayas, L. E. (2010). Evaluating qualitative research for social work practitioners. Advances in Social Work, 11(2), 188-202.

IASSW \& IFSW. (2014). Global definition of social work. http://ifsw.org/get-involved/global-definition-of-socialwork/

Maher, P., \& Maidment, J. (2013). Social work disaster emergency response within a hospital setting. New Zealand New Zealand Social Work, 25(2), 69-76.

Milner, V. (2013). In the zone: Keeping hope alive through shaky times. New Zealand New Zealand Social Work, 25(2), 45-57.

Paul, B. K. (2011). Environmental hazards and disasters: Contexts, perspectives and management. WileyBlackwell.
Ritchie, J., Lewis, J., McNaughton Nicholls, C., \& Ormston, R. (2014). Qualitative research practice: A guide for social science students and researchers. SAGE.

Shevellar, L., \& Westoby, P. (2014). "Perhaps?" and "Depends!" The possible implications of disaster related community development for social work. Advances in Social Work and Welfare Education, 16(2), 23-35.

Tan, N. T., \& Yuen, F. (2013). Social work, strengths perspective, and disaster management: Roles of social workers and models for intervention. Journal of Social Work in Disability \& Rehabilitation, 12, 1-7. doi:10.1080/ 1536710X.2013.784170

Tudor, R., Maidment, J., Campbell, A., \& Whittaker, K. (2015). Examining the role of craft in post-earthquake recovery: Implications for social work practice. British Journal of Social Work, 45 (suppl_1), i205-i220. doi:10.1093/bjsw/bcv126

van Heugten, K. (2014). Human service organizations in the disaster context. Palgrave Macmillan. 